\title{
Refleksija Štamparove javno-zdravstvene djelatnosti na području Slavonskoga Broda
}

\author{
Stjepan Čeović \\ Slavonski Brod \\ Ivica Balen \\ Slavonski Brod \\ ivekbalen@gmail.com
}

SAŽETAK: Aktivnost javnozdravstvene službe u Slavonskom Brodu započinje već u vrijeme Vojne granice, kada je organiziran sanitarni kordon i karantena da bi se spriječilo prenošenje opasnih zaraznih bolesti preko Save. Ipak, razvijenija preventivna djelatnost slijedila je u vrijeme djelovanja Andrije Štampara, jer se osniva Školska poliklinika, održavaju javnozdravstvena predavanja, započinje rad Antituberkuloznoga dispanzera, Ambulante protiv veneričnih bolesti te Stanice protiv bjesnoće. Velik je napredak učinjen 1946. godine osnivanjem Sanitarno-epidemiološke stanice kao zasebne institucije. Pokazala se vrlo uspješnom u suzbijanju poslijeratne epidemije trbušnoga tifusa, eradikaciji malarije i uvođenju masovnoga cijepljenja protiv dječjih zaraznih bolesti. Kroz četrdesetgodišnje razdoblje, u okviru Medicinskoga centra slijedila je izvjesna stagnacija, napose u usporedbi s velikim progresom kliničkih i dijagnostičkih grana medicine. Osnivanjem Županijskog zavoda za javno zdravstvo 1994. godine preventivna djelatnost doživljava znatni razvitak. To se posebno odnosi na praćenje i suzbijanje kroničnih degenerativnih bolesti, malignih tumora, zaštitu školske djece i mladeži, kao i na osvješćivanje sve češće prisutne bolesti ovisnosti u mladoj populaciji.

Ključne riječi: zdravstvene službe; Slavonski Brod

\section{Štamparovo vrijeme}

Tradicija javnozdravstvenoga djelovanja u Slavonskom Brodu je duga jer je Brod bio oko stoljeće i pol sastavni dio Vojne granice između Austro-Ugarskoga i Osmanskoga Carstva koja je je u svojem sastavu imala Sanitarni kordon s karantenama. Na čelu tih institucija bili su vojni liječnici kojima je osnovni zadatak bio suzbijanje širenja opasnih zaraznih bolesti preko Save. Isti sanitarni liječnik provodio je sanitarne mjere među vojskom i civilnim stanovništvom. 


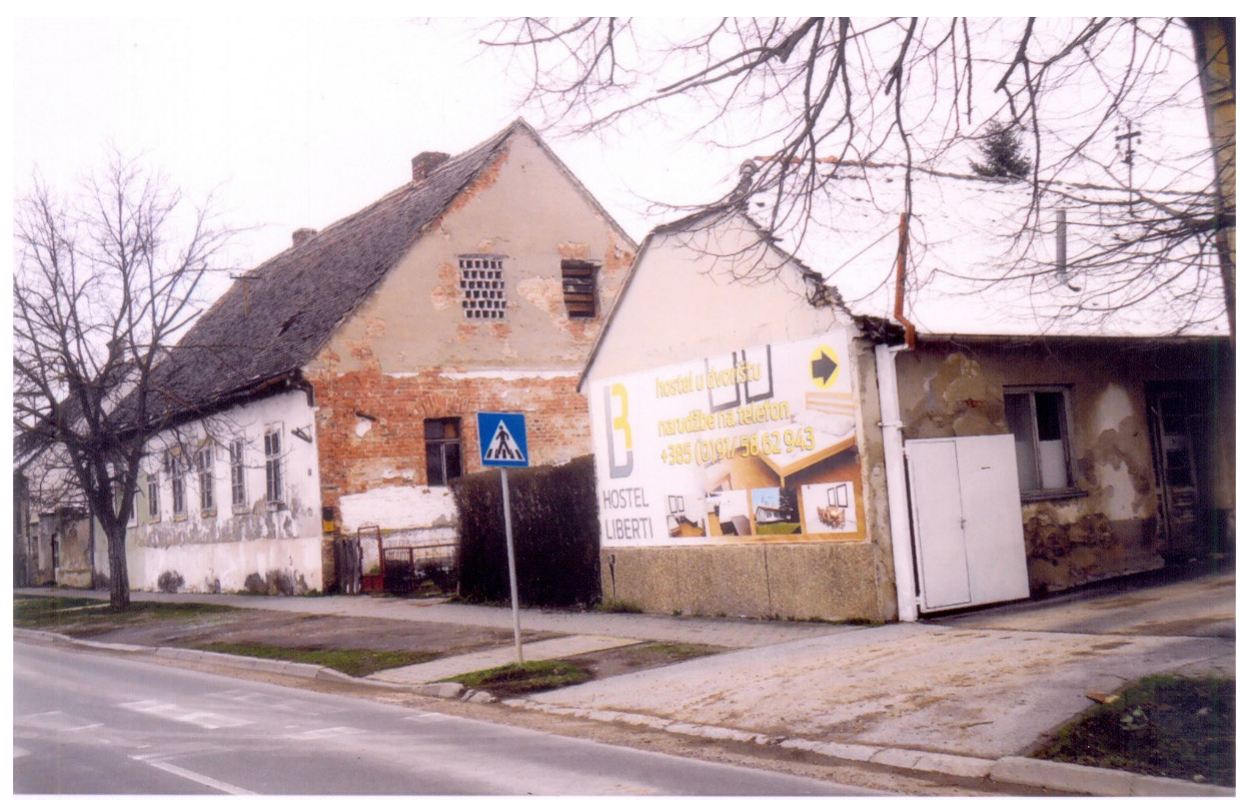

Slika 1. Zgrada direktora Karantene i ulaz u izolaciju

U prvoj polovici XX. stoljeća, pojavom i djelovanjem Andrije Štampara na čelu Higijenskoga odjela Ministarstva zdravlja u Beogradu od 1920. do 1931. godine i njegova energičnoga zalaganja za »zdravlje za sve«, širom bivše Kraljevine SHS (Jugoslavije) niknulo je oko 250 javnozdravstvenih ustanova. Domovi zdravlja, dispanzeri, poliklinike, antimalarične stanice i higijenski zavodi premrežili su cijelu državu.

Odjek tih aktivnosti bilo je osnivanje Školske poliklinike u Brodu na Savi 1925. godine, sa zadaćom čuvanja i unaprjeđenja zdravlja školske djece i mladeži. Održavana su i mnogobrojna javnozdravstvena predavanja za pučanstvo s temama borbe protiv tuberkuloze, trahoma, drugih zaraznih bolesti te alkoholizma i pušenja ${ }^{1}$. Koliko je velik bio problem $\mathrm{s}$ trahomom pokazalo se nakon dolaska prvoga specijalista za očne bolesti dr. Kamila Bivala u Slavenski Brod iste godine i podatka da je na području Velike Kopanice pronađeno 360 oboljelih od te bolesti² ${ }^{2}$ Nadalje, u pokušaju borbe protiv tuberkuloze, koja je također bila vrlo raširena bolest, osniva se u tridesetim godinama Antituberkulozni dispanzer. Godine 1937. otvorena je Stanica

1 Jović, D. »Razvoj zdravstvene službe u prvoj deceniji postojanja Kraljevine SHS (1919.-1928.)《. U: A. Jelić (ur.), Razvoj zdravstva na području Općine Slavonski Brod. Slavonski Brod: Historijski institut Slavonije i Baranje, Slavonski Brod 1975; Zapisi dr. Mije Pišla, liječnika u Donjim Andrijevcima (1893.1985.). Gradska knjižnica u Slavonskom Brodu.

2 Konjević, M. »Zdravstvene prilike u Brodu od 1929.-1941.«. U: A. Jelić (ur.), Razvoj zdravstva na području Općine Slavonski Brod. Slavonski Brod: Historijski institut Slavonije i Baranje, Slavonski Brod 1975. 
protiv bjesnoće, smještena u zgradi Školske poliklinike, a zatim i Ambulanta protiv veneričnih bolesti. Bolesti kojima se pokušavalo suprotstaviti imale su uočljivo socijalno obilježje.

Sve ove hvalevrijedne aktivnosti Andrije Štampara nailazile su na otpore, često i kod samih liječnika koji su se suprotstavljali besplatnom liječenju u Antiveneričnom i Antituberkuloznom dispanzeru. Zbog sličnih problema sukob je na razini države počeo već ranije, zbog čega je Štampar 1924. godine prekinuo članstvo u Zboru liječnika Hrvatske. Međutim ništa ga nije moglo pokolebati u dalinjoj borbi za svoje principe i ideale, koje je taksativno objavio u deset točaka. Njegove ideje o unaprjeđenju narodnoga zdravlja ubrzo su prepoznate u Ligi naroda i Rockfellerovoj fondaciji: kao stručnjak Zdravstvene sekcije, bio je angažiran širiti svoje ideje Europom i SAD-om te poslan u Kinu.

\section{Sanitarno-epidemiološka stanica (SES)}

Nakon Drugoga svjetskog rata Štampar je ponovno zauzeo visoke društvene funkcije, stoga se osjećalo njegovo djelovanje na javno zdravstvo. Koncem 1946. godine u Slavonkom se Brodu osnovala Okružna sanitarno-epidemiološka stanica ${ }^{3}$, koja se sastojala od Epidemiološkoga, Bakteriološkoga i Serološkoga odjela te Laboratorija za pregled pitke vode. Bila je nadležna za Slavonski Brod, Đakovo i Slavonsku Požegu, odnosno za područje od Pakraca na zapadu do Vinkovaca i Županje na istoku. U ustanovi je ukupno bilo 11 stručnih i četiri administrativne osobe. Bila je to prva samostalna javnozdravstvena ustanova u Slavonskom Brodu koja je organizirano pratila cjelokupnu javnozdravstvenu problematiku. Nakon ukidanja okruga 1947. godine nadležnost SES-a svodila se samo na područje Slavonskoga Broda i okolice. Nedugo zatim SES je dobio svoju prvu veliku ulogu u suzbijanju epidemije trbušnoga tifusa u proljeće 1947. godine.

Epidemija se vrlo brzo širila među gradskim stanovništvom najvjerojatnije hidričnim putem, a potom kontaktom i na seosko područje. Prethodna zima, 1946., bila je vrlo snježna pa je u proljeće zboga visokog vodostaja Save nastalo spajanje vodonosnih slojeva plitko kopanih bunara, septičkih jama i u ratu oštećene kanalizacijske mreže. Prema dnevniku doktora Milenka Kajganovića, sanitarnoga inspektora u Brodu, tijekom iste godine oboljele su 622 osobe, a sljedeće godine 183, da bi se u blagom obliku epidemija vukla još dvadesetak godina ${ }^{4}$. Od početka se krenulo s hitnim mjerama suzbijanja. Djelatnici SES-a provodili su kloriranje svih bunara u gra-

3 Izvještaj Narodnog odbora općine od 17. 12.1946. Hrvatski arhiv Slavonski Brod, k. 10.

4 Kajganović, M. Higijensko epidemiološki problemi grada i kotara Slavonski Brod 1952., str. 1-11. Arhiv Zavoda za javno zdravstvo Brodsko-posavske županije. 
du, cijepljenje stanovništva, ispitivanje kliconoštva i javnozdravstvena predavanja. Cijepljenjem, kojim je rukovodio dr. Dinko Berković, u prvim je mjesecima bilo obuhvaćeno čak 8500 ljudi, a sljedeće godine docijepljeno je još 350 osoba. Prema nekim izvorima broj cijepljenih bio je i puno veći. Bakteriološki pregledi obavljani su dijelom u SES-u Slavonskoga Broda, a dijelom u Higijenskom zavodu u Osijeku, dok je fagotipizacija Salmonella određivana u Zagrebu. U bakteriološkom laboratoriju SES-a radio je vrlo stručan laboratorijski tehničar Aleksandar Černjak, a naknadno je zaposlena i doktorica Bratuša, liječnica opće medicine iz Vinkovaca. Doktor Kajganović krenuo je slati apele gradskoj upravi za početak izgradnje vodovodnoga sustava, što je često ponavljao jer se ova aktivnost odvijala vrlo sporo. Prvi bunar budućega vodovoda iskopan je na Jelasu tek 1950. godine, a izgradnja vodovodne mreže uzela je ozbiljnoga maha tek 1960. godine pa nadalje.

U okvirima akcije suzbijanja malarije u cijeloj Jugoslaviji u 1950-im godinama, SES u Slavonskom Brodu bio je pred novim izazovom. Koncepcija eradikacije sastojala se od više faza, najprije pripremom stručnih kadrova, nabavkom insekticida i tehničkih sredstava (jednoručne i dvoručne štrcaljke). Slijedila je udarna faza tretiranjem insekticidima produženoga djelovanja (DDT) svih nastanjenih prostora u selu i gradu ${ }^{5}$. Nakon toga nadovezala se treća faza, u kojoj su se otkrivali novooboljeli bolesnici među domaćim stanovništvom. Uspjeh je bio izvanredan jer je malarija do sredine 1950-ih nestala. Na području bivše Jugoslavije, Hrvatska i Vojvodina prve su uspjele eradicirati malariju, dok je u drugim dijelovima zemlje malarija bila prisutna još desetak godina. Zadnji bolesnik od malarije u Hrvatskoj je zabilježen 1954. godine ${ }^{6}$.

U okvirima SES-a obavljali su se i svi poslovi sanitarne inspekcije, kojih je bilo mnogo. Uskoro se SES sjedinio s Gradskom izvanbolničkom poliklinikom, a 1952. godine, kad se ujedinjenjem cijele izvanbolničke djelatnosti formirao Dom zdravlja, SES je promijenio naziv u Higijensko-epidemiološku službu, kojoj su zadatci ostali isti. Pojam SES-a ostao je ipak dugo u upotrebi, pa čak i u okviru Medicinskoga centra kada su se 1957. godine spojile izvanbolnička i bolnička služba u jednu ustano$\mathrm{vu}^{7}$, što samo dokazuje da je SES i pored svih problema svoje zadatke obavljao odgovorno i uspješno.

5 Usmeno priopćenje sanitarnog tehničara u mirovini Stjepana Pocrnića Stjepanu Čeoviću iz 2011.

6 Miletić-Medved, M., Božikov, J., Užarević Z. »Branko Cvjetanović i Branimir Richtersuradnici Andrije Štampara«. Anali Zavoda za znanstveni i umjetnički rad u Osijeku, Zagreb-Osijek, 2012., sv. 28, str. 103-113.

7 Rješenje o osnivanju Zdravstvenog centra u Slavonskom Brodu od 15. 2. 1957. Zajednička sjednica obaju vijeća Narodnog odbora općine Slavonski Brod. Hrvatski arhiv u Slavonskom Brodu, f. NOO, k. 33 . 


\section{Higijensko-epidemiološka služba (HE)}

Uloga HE službe u Medicinskom centru iduća nepuna četiri desetljeća bila je proklamirana kao temeljni činitelj očuvanja narodnoga zdravlja. U svim dokumentima i sistematizacijama to se posebno naglašavalo. Stvarnost je ipak bila drugačija. Ubrzano je rasla potreba za zbrinjavanjem sve većega broja osiguranih osoba, a posebno nakon uključivanja poljoprivrednih domaćinstava, tako da su pojedine kliničke i dijagnostičke grane bile pod sve većim pritiskom povećanoga broja bolesnika, zbog čega su se morale širiti i prostorom i osobljem. Sredinom 1960-ih i 1970-ih godina u bolničkom krugu izgrađene su dvije velike zgrade za potrebe bolničkih odjela, dok je HE služba s Mikrobiologijom i Laboratorijem za ispitivanje vode i živežnih namirnica smještena u adaptiranu zgradu izgrađenu 1950-ih godina za bolničku ljekarnu. Ta se zgrada ubrzo pokazala neadekvatnom jer su zidovi bili puni vlage, a često je $\mathrm{i}$ krov prokišniavao.

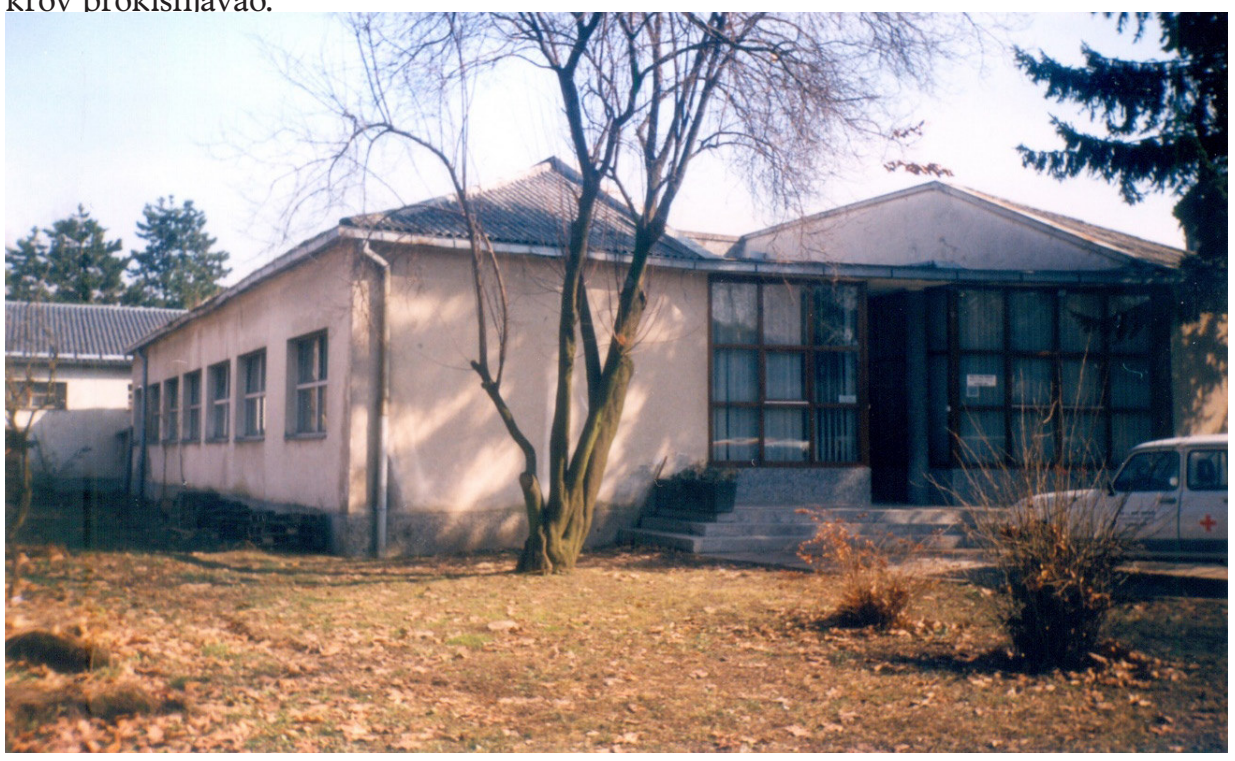

Slika 3. Zgrada Higijensko-epidemiološke službe od 1967. do 1996. godine

Od kraja Drugoga svjetskog rata pa do 1967. godine HE služba obavljala je cjelokupno obavezno cijepljenje predškolske i školske djece. Od tada cijepljenja prelaze u nadležnost Službe za zaštitu zdravlja djece, Školske medicine i Zdravstvenih stanica u selima, čime je HE služba trebala biti rasterećena dijela svojih obaveza, ali je istodobno morala trajno nadzirati kontinuirano obavljanje cijepljenja na svim dislociranim mjestima. Taj su posao obavljali epidemiolog, sanitarni inspektor i rukovoditelj Službe za zaštitu zdravlja djece. Nakon desetak godina redovitoga cijepljenja, uz dostup- 
nost antibiotika kod streptokoknih bolesti, većina zaraznih bolesti dječje dobi prestala je biti javnozdravstveni problem.

Nastala situacija omogućila je Epidemiološkoj službi da se okrene i drugim javnozdravstvenim problemima. Pozornost se stavlja na kronične nezarazne bolesti, primjerice na hipertenziju, dijabetes, prekomjernu tjelesnu težinu te bolesti koje su povezane s lošim navikama. U našem je kraju poseban izazov epidemiologu bila pojava endemske nefropatije uočene krajem 1950-ih godina. Bolest je primijećena u desetak sela zapadne Brodske Posavine, što je bila jedina lokacija u Hrvatskoj, dok su ostala žarišta bila u Bosni, Srbiji, Bugarskoj i Rumunjskoj. Endemska nefropatija je kronična bubrežna bolest nepoznata uzroka, progresivnoga toka i smrtnoga ishoda. U skladu sa Štamparovom idejom da liječnik treba tražiti bolesnika, Epidemiološka služba osnovala je isturenu terensku ambulantu u Kaniži, selu kamo je epidemiolog odlazio dvaput tjedno više od dvadeset godina (1970-92). U toj je ambulanti epidemiolog pregledavao sve pridošle bolesnike s namjerom da upozna cjelokupnu populaciju, ponajprije njihove navike, običaje, način života, prehranu i rodbinske veze. Istodobno su se organizirali obiteljski pregledi cijeloga stanovništva, ne samo u Kaniži nego i u ostalih desetak sela koja su bila zahvaćena tom bolešću. Na temelju anamneze, kliničkoga pregleda i laboratorijskih nalaza, dobio se uvid u proširenost bolesti, određivala se incidencija, prevalencija i letalitet. Zatim se epidemiolog povezivao sa stručnim i znanstvenim republičkim institucijama u Zagrebu, a preko njih i sa znanstvenicima iz Europe i SAD-a. HE odjel sudjelovao je u desetak poduzetih znanstvenih projekata, koji su dokazali da bolest nije primarno hereditarne naravi i pored obolijevanja više članova iz iste obitelji. Utvrđeno je da je za pojavu bolesti odgovoran dugogodišnji boravak, način života i rada u endemskoj seoskoj sredini ${ }^{8}$. Na temelju ovih spoznaja pokrenuta je široka aktivnost u zajednici. Izgrađena je vodovodna mreža za sva ugrožena sela, produbila se i proširila kanalska mreža za odvod oborinskih i zaobalnih voda, asfaltirale su se ceste, osnovali proizvodni pogoni, izgradile velika nova Zdravstvena stanica i nova Osnovna škola u Bebrini. Sve to pridonosi porastu higijenskoga standarda pučanstva, kao i promjeni nekih važnih ekoloških čimbenika.

Uz praćenje endemske nefropatije, HE služba rješavala je i sve druge redovne obaveze, primjerice nadzor nad osobljem u proizvodnji prehrambenih namirnica, kontrolu javne vodoopskrbe i prehrane, suzbijanje hospitalnih infekcija, održavanje tečajeva higijenskoga minimuma te već spomenutu kontrolu obaveznoga cijepljenja.

Kroz dugogodišnje zajedništvo u Medicinskom centru događale su se razne organizacijske promjene. HE služba dospjela je u Osnovnu organizaciju udruženoga

8 Čeović, S. Endemska nefropatija u različitim etničkim skupinama. Disertacija. Zagreb: Medicinski fakultet Sveučilišta u Zagrebu, 1978., 1-117. 
rada (OOUR) Primarne djelatnosti, a Mikrobiologija i Laboratorij za ispitivanje vode i hrane u Dijagnostički OOUR. Ostao im je zajednički radni prostor, u kojem nije bilo uvjeta za daljnji razvoj.

\section{Županijski zavod za javno zdravstvo}

Jedan od najdjelotvornijih poteza u reformi zdravstva 1994. godine bilo je osnivanje Zavoda za javno zdravstvo. Od samoga početka Zavod je krenuo u nagli razvoj energično, uporno i smišljeno na svim zasadama javnozdravstvenih ideja Andrije Štampara. Za početak je bilo neophodno izgraditi potrebni radni prostor. Na mjestu stare zgrade, površine oko 500 kvadratnih metara, podignuta je trostruko veća nova, koja je službeno otvorena 1998. godine. Od Laboratorija za ispitivanje živežnih namirnica proširenjem je nastala Služba za zdravstvenu ekologiju. Ukidanjem Službe školske medicine, u Zavodu se osniva Služba preventivne školske medicine.

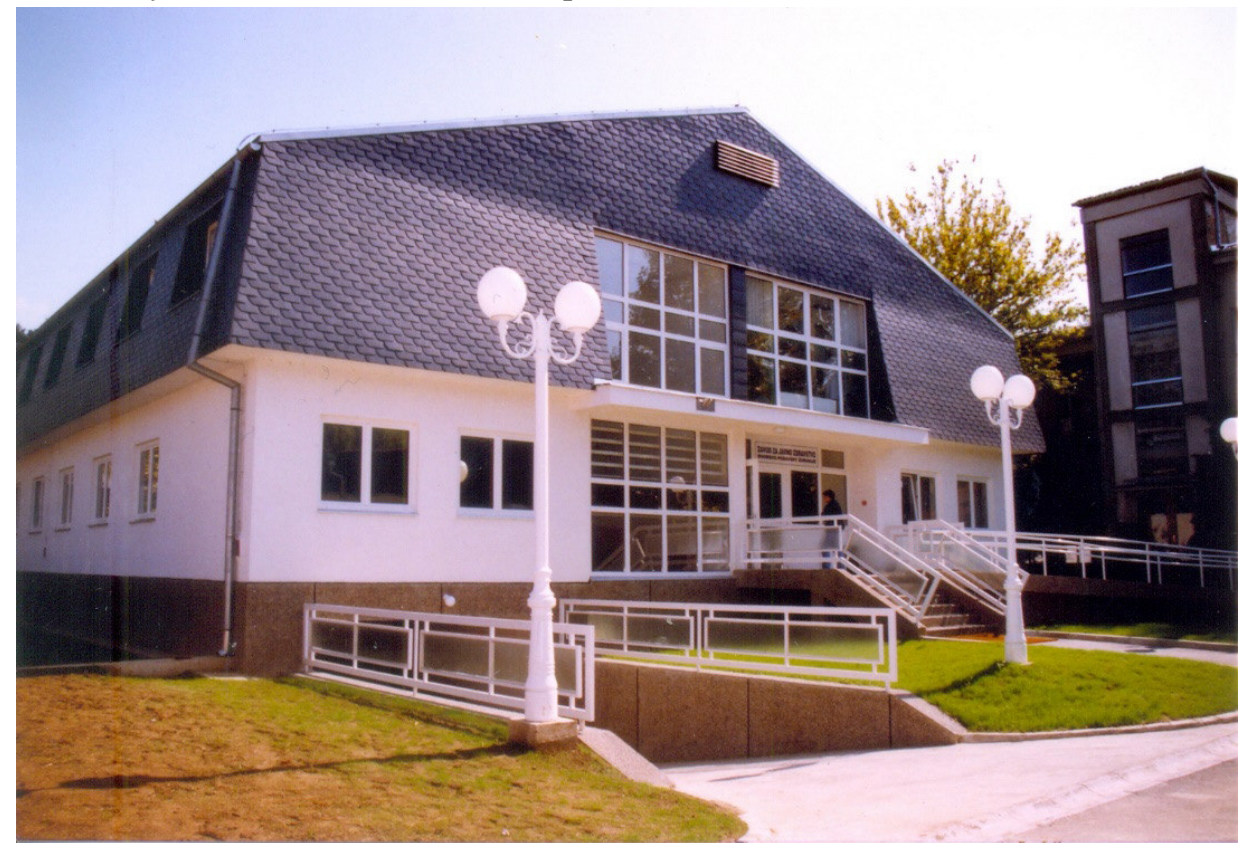

Slika 4. Zavod za javno zdravstvo, izgrađen 1997. godine

Idućih godina osniva se i nova služba, Služba za zaštitu mentalnog zdravlja, prevenciju i izvanbolničko liječenje ovisnosti. Osnutkom novih službi i porastom kadrova ubrzo se ukazala potreba za izgradnju dodatnih novih prostora. Tada je odlučeno da se izgradi još jedna nova zgrada izvan bolničkoga kruga u Cesarčevoj ulici. Kako su od početka Zavodi za javno zdravstvo planirani kao županijske ustanove, slijedilo je 
objedinjavanje javnoga zdravstva Slavonskoga Broda i Nove Gradiške. Zbog toga je nastala potreba za trećom novom zgradom, koja je uskoro nastala u krugu bolnice u Novoj Gradiški.

Današnji Županijski zavod za javno zdravstvo, na svoje tri lokacije, ima 67 zaposlenika. U krugu brodske bolnice nalaze se službe za epidemiologiju, mikrobiologiju i zdravstvenu ekologiju. U Cesarčevoj ulici su Služba za školsku preventivnu medicinu i Služba za javnozdravstvenu zaštitu mentalnoga zdravlja i prevenciju te izvanbolničko liječenje ovisnosti. Sve se te službe, osim Mikrobiologije, nalaze se i u Novoj Gradiški.

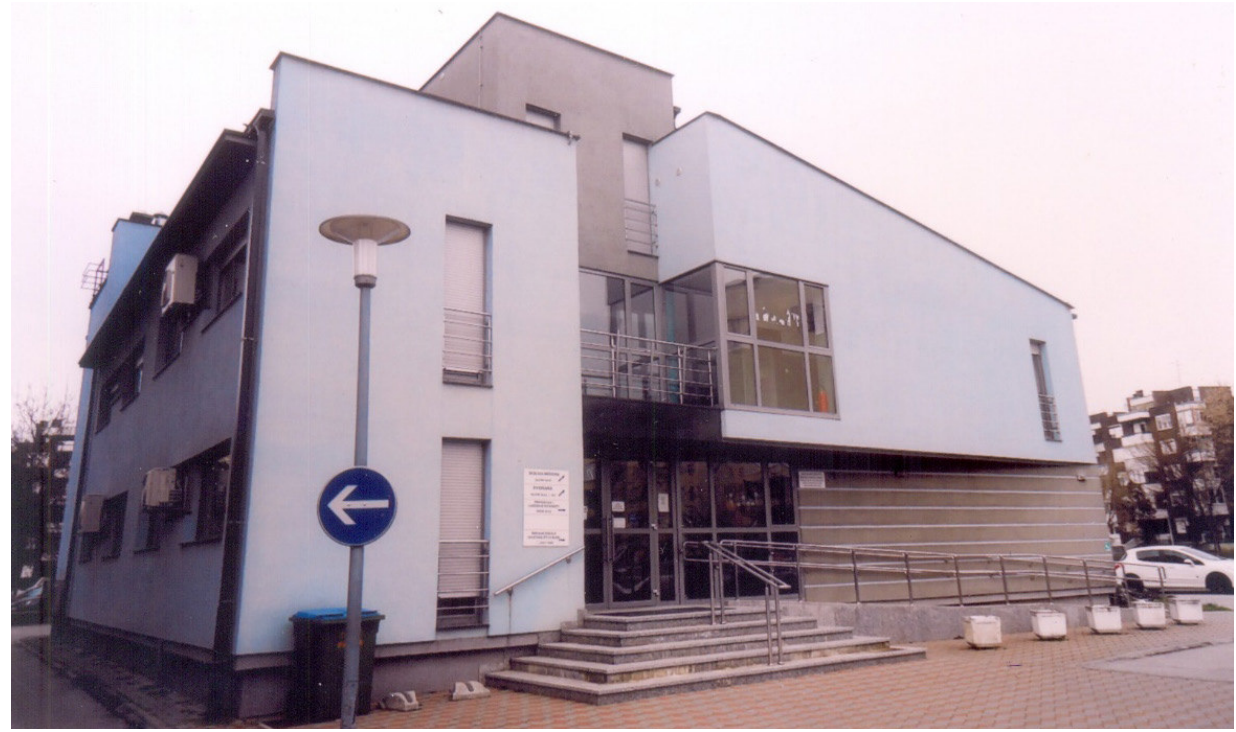

Slika 5. Preventivna i školska medicina Zavoda za javno zdravstvo u Cesarčevoj ulici

Današnji cilj vrlo razvijenoga Zavoda usmjeren je suvremenim javnozdravstvenim potrebama ovoga kraja: kontrola novih i svih klasičnih zaraznih bolesti, suzbijanje malignih bolesti, pretjerane tjelesne težine, prevencija ateroskleroze te borba protiv loših životnih navika i bolesti ovisnosti, osobito kod mladih ljudi. Trajno se kontroliraju javna prehrana i vodoopskrba. U skladu sa Štamparovim postavkama, svi navedeni zadatci izvode se s čvrstim uvjerenjem da ulaganje u njihovo ostvarenje donosi najveću korist u čuvanju i unaprjeđenju zdravlja. Djelatnici Zavoda vrlo su aktivni: do 2011. godine publicirali su 312 stručnih i znanstvenih radova, a do 2018. obranili pet doktorskih disertacija, sve iz djelokruga javnoga zdravstva Brodsko-posavske županije9

9 Cvitković, A. Čeović S. Kronika javnog zdravstva i Zavoda za javno zdravstvo Brodsko-posavske županije. Zavod za javno zdravstvo Brodsko-posavske županije: Slavonski Brod, 2011., str. $155-173$. 


\section{Zaključak}

Tradicija javnozdravstvene djelatnosti u Slavonskom Brodu je duga, započinje već u vrijeme Vojne granice, kada je organiziran sanitarni kordon i karantena da bi se spriječilo prenošenje opasnih zaraznih bolesti preko Save. Razvijenija preventivna djelatnost slijedila je u vrijeme djelovanja Andrije Štampara, svjetski poznatoga pionira javnozdravstvene službe. Njegovo djelovanje pokreće razvoj javnoga zdravstva, jer se osniva Školska poliklinika, održavaju javnozdravstvena predavanja, započinje rad Antituberkuloznoga dispanzera, Ambulante protiv veneričnih bolesti te Stanice protiv bjesnoće. Novi iskorak slijedi nakon Drugoga svjetskog rata osnivanjem Sanitarno-epidemiološke stanice kao zasebne institucije. Pokazala se vrlo uspješnom u suzbijanju poslijeratne epidemije trbušnoga tifusa, eradikaciji malarije te u uvođenju masovnoga cijepljenja protiv dječjih zaraznih bolesti. Integracijom zdravstvene službe u Medicinski centar 1957. godine, slijedila je stagnacija, posebno u usporedbi s velikim progresom kliničkih i dijagnostičkih grana medicine. Novi uzlet slijedi osnivanjem Županijskoga zavoda za javno zdravstvo 1994. godine. To se posebno odnosi na praćenje i suzbijanje kroničnih degenerativnih bolesti, malignih tumora, zaštitu školske djece i mladeži, kao i stavljanje pozornosti na sve češće prisutne bolesti ovisnosti u mladoj populaciji, ali i na razvoj pojedinih službi te izgradnju novih prostora za znatno bolje uvjete rada.

\section{LITERATURA}

Cvitković, A., Čeović, S.: Kronika javnog zdravstva i Zavoda za javno zdravstvo Brodsko-posavske županije. Zavod za javno zdravstvo Brodsko-posavske županije: Slavonski Brod, 2011., str. 155-173.

Čeović, S.: Endemska nefropatija u različtim etničkim skupinama. Disertacija. Zagreb: Medicinski fakultet Sveučilišta u Zagrebu, 1978., 1-117.

Izvještaj Narodnog odbora općine od 17. 12. 1946. Hrvatski arhiv Slavonski Brod, k. 10.

Jović, D.: »Razvoj zdravstvene službe u prvoj deceniji postojanja Kraljevine SHS (1919.-1928.)《. U: A. Jelić (ur.), Razvoj zdravstva na području Općine Slavonski Brod. Slavonski Brod: Historijski institut Slavonije i Baranje, Slavonski Brod 1975.

Kajganović, M.: Higijensko epidemiološki problemi grada i kotara Slavonski Brod 1952., str. 1-11. Arhiv Zavoda za javno zdravstvo Brodsko-posavske županije.

Konjević, M.: »Zdravstvene prilike u Brodu od 1929.-1941.«. U: A. Jelić (ur.), Razvoj zdravstva na području Općine Slavonski Brod. Slavonski Brod: Historijski institut Slavonije i Baranje, Slavonski Brod 1975.

Miletić-Medved, M., Božikov, J., Užarević, Z.: »Branko Cvjetanović i Branimir Richter-suradnici Andrije Štampara«, Anali Zavod za znanstveni i umjetnički rad u Osijeku, Zagreb-Osijek, 2012. sv. 28, str. 103-113.

Rješenje o osnivanju Zdravstvenog centra u Slavonskom Brodu od 15. 2. 1957. Zajednička sjednica obaju vijeća Narodnog odbora općine Slavonski Brod. Hrvatski arhiv u Slavonskom Brodu, f. NOO, k. 33.

Usmeno priopćenje sanitarnog tehničara u mirovini Stjepana Pocrnića Stjepanu Čeoviću iz 2011.

Zapisi dr. Mije Pišla, liječnika u Donjim Andrijevcima (1893.-1985.). Gradska knjižnica u Slavonskom Brodu. 


\title{
ECHOES OF ŠTAMPAR'S PUBLIC HEALTH ACTIVITIES IN THE SLAVONSKI BROD
} AREA

\author{
Stjepan Čeović \\ Slavonski Brod \\ Ivica Balen \\ Slavonski Brod \\ ivekbalen@gmail.com
}

\begin{abstract}
The activities of the public health service in Slavonski Brod began already at the time of the Military Border, when a cordon sanitaire and quarantine were established to prevent the transmission of dangerous infectious diseases across the Sava River. However, a more developed form of preventive medicine was introduced during the time of Andrija Štampar, involving the establishment of the School Polyclinic, the holding of public health lectures, and the founding of the Anti-Tuberculosis Dispensary, the Anti-Venereal Clinic, and the Anti-Rabies Station. A major advance was made in 1946, when the Sanitary-Epidemiological Station was established as a separate institution. It proved very successful in combating the post-war epidemic of abdominal typhus, eradicating malaria, and introducing mass vaccination against children's infectious diseases. A sort of stagnation followed during the 40-year period within the frame of the Medical Centre, especially when compared to the great progress of clinical and diagnostic medicine. Preventive activity developed significantly after the founding of the County Institute of Public Health in 1994. This is particularly applicable to the monitoring and combating of chronic degenerative diseases, malign tumours, protection of schoolchildren and youths, and increasing attention given to addictive disorders among the younger population.
\end{abstract}

Keywords: health services; Slavonski Brod 